\title{
Post-conflict household structures and underweight: a multilevel analysis of a community-based study in northern Uganda
}

\author{
Stine Schramm ${ }^{1, *}$, Jannie Nielsen ${ }^{2,3}$, Felix O Kaducu ${ }^{4}$, Ceaser L Okumu ${ }^{4}$, Emilio Ovuga ${ }^{5}$ \\ and Morten Sodemann ${ }^{1,6}$ \\ ${ }^{1}$ Centre for Global Health, Department of Clinical Research, University of Southern Denmark, Albani Torv 6, 5000 \\ Odense C, Denmark: ${ }^{2}$ Global Health Section, Department of Public Health, University of Copenhagen, Copenhagen, \\ Denmark: ${ }^{3}$ Emory Global Diabetes Research Center, Rollins School of Public Health, Emory University, Atlanta, GA, \\ USA: ${ }^{4}$ Department of Public Health, Faculty of Medicine, Gulu University, Gulu, Uganda: ${ }^{5}$ Department of Mental \\ Health, Faculty of Medicine, Gulu University, Gulu, Uganda: ${ }^{6}$ Migrant Health Clinic, Department of Infectious \\ Diseases, Odense University Hospital, Odense, Denmark
}

Submitted 7 November 2017: Final revision received 9 May 2018: Accepted 15 May 2018: First published online 18 June 2018

\begin{abstract}
Objective: To examine associations between household-level characteristics and underweight in a post-conflict population.

Design: Nutritional status of residents in the Gulu Health and Demographic Surveillance Site was obtained during a community-based cross-sectional study, $\sim 6$ years after the civil war. Household-level factors included headship, polygamy, household size, child-to-adult ratio, child crowding, living with a stunted or overweight person, deprived area, distance to health centre and socio-economic status. Multilevel logistic regression models examined associations of household and community factors with underweight, calculating OR, corresponding $95 \% \mathrm{CI}$ and intraclass correlation coefficients. Effect modification by gender and age was examined by interaction terms and stratified analyses.

Setting: Rural post-conflict area in northern Uganda.

Subjects: In total, 2799 households and 11312 individuals were included, representing all age groups.

Results: Living in a female-headed $v$. male-headed household was associated (OR; $95 \% \mathrm{CI})$ with higher odds for underweight among adult men $(2 \cdot 18 ; 1 \cdot 11,4 \cdot 27)$ and girls $<5$ years $(1.51 ; 0.97,2 \cdot 34)$, but lower odds among adolescent women aged 13-19 years $(0 \cdot 46 ; 0 \cdot 22,0 \cdot 97)$. Higher odds was seen for residents living in deprived areas $(1.37 ; 0.97,1.94)$, with increasing distance to health services $(P$-trend $<0.05)$ and among adult men living alone $v$. living in an average-sized household of seven members $(3 \cdot 23 ; 1 \cdot 22,8 \cdot 59)$. Residents living in polygamous households had lower odds for underweight $(0 \cdot 79 ; 0 \cdot 65,0.97)$.

Conclusions: The gender- and age-specific associations between household-level factors and underweight are likely to reflect local social capital structures. Adapting to these is crucial before implementing health and nutrition interventions.
\end{abstract}

\author{
Keywords \\ Nutrition \\ Gender \\ Post-conflict \\ Social capital \\ Internally displaced persons
}

By the end of 2016, 40.3 million people were internally displaced due to conflict and violence worldwide - the second highest figure ever reported and twice the number of refugees ${ }^{(1)}$. At the same time, the highest number of internally displaced persons returning was also recorded $(6.5 \text { million })^{(1)}$. While the immediate health impacts of war and displacement are well established ${ }^{(2-5)}$, less is known about the population's health status in post-conflict areas ${ }^{(6)}$. Not only armed conflict, but also the early state of peace may create harsh conditions, such as forced migration and collapsed infrastructure ${ }^{(7)}$. In northern Uganda, a 20-year long (1986-2006) armed conflict forced $\sim 1.8$ million people ( $90 \%$ of the population) into camps for internally displaced persons $^{(8)}$. From 2008 to 2011, the Ugandan Government conducted a resettling programme for people to move from camps to their ancestors' homes in rural areas. New public health challenges compared with living in camps followed, including higher food insecurity and reduced access to health services, schools and trading markets $^{(9)}$. In the postconflict period, the global acute malnutrition rates among 
children aged 6-59 months were higher ${ }^{(10)}$ than reported during the insurgency ${ }^{(11)}$. Additionally, the prevalence of adult underweight was higher in the post-conflict area compared with national rural estimates in $2011^{(12)}$. Previous nutrition studies in post-conflict settings have focused primarily on children $<5$ years of age and individual-level risk factors $^{(13-18)}$. Moreover, food security and health programmes by humanitarian organizations often focus on conventional target groups such as female-headed households, pregnant women, children and disease-specific groups $^{(19,20)}$. However, household-level factors may play an important role in alleviating and preventing malnutrition in post-conflict settings ${ }^{(18)}$. In sub-Saharan Africa nonconflict settings, inconsistent associations between household-level factors and child underweight have been reported, including polygamous marriages and household size $^{(21-24)}$ and headship ${ }^{(25,26)}$. Vella et al. found that child crowding, distance to health centre, latrine ownership and household wealth were important factors for child nutritional status in south-west Uganda (non-conflict setting) ${ }^{(27)}$. In northern Uganda, the conflict and post-conflict situation have affected various aspects of the traditional household structures and characteristics, such as household size, headship and location. For example, excess mortality among men during the war and changes in marital conducts have led to more female-headed households ${ }^{(8,28-30)}$. Traditionally in northern Uganda, men are the economic providers for the household and women have limited rights to own land ${ }^{(7)}$. Thus, female-headed households may be associated with lower socio-economic status (SES), food insecurity and poorer nutritional outcomes ${ }^{(25)}$. To our knowledge, the influence of household-level factors on nutritional status has not previously been studied among groups other than children, neither in general nor in a postconflict setting with markedly changing gender roles and household structures. The aim of present study was to examine associations between household-level characteristics and underweight among all age groups in the postconflict area of northern Uganda.

\section{Methods}

\section{Study setting and population}

The current cross-sectional study was conducted in 20112013 at the Gulu Health and Demographic Surveillance Site (HDSS) in northern Uganda ${ }^{(12)}$. The Gulu HDSS covers a rural area of $250 \mathrm{~km}^{2}$ named Awach sub-county of Gulu District, $30 \mathrm{~km}$ from Gulu Municipality. The population are mainly peasants relying on small-scale subsidized farming. All registered residents of the Gulu HDSS were eligible to participate ( $n 16523$ in 2012). Trained field assistants visited the households and interviewed residents aged $\geq 15$ years, and caregivers were interviewed about residents aged $0-15$ years. In cases where household members were not present, the household was revisited up to three times. Overall, household non-response was $11.2 \%$ ( $n$ 353 ) and the individual non-response was $28.5 \%$ ( $n$ 4730). Among non-responding individuals, $45.9 \%$ were female, the median age was $15 \cdot 1$ (interquartile range $7 \cdot 2-26 \cdot 8$ ) years and $31.9 \%$ were school-aged children aged 514 years.

\section{Antbropometry}

Weight and height were measured with participants wearing light clothes and without shoes. Weight was measured to the nearest $0.5 \mathrm{~kg}$ using a mechanical flat scale (Seca model 762, Germany). Height was measured to the nearest $0 \cdot 1 \mathrm{~cm}$ using wooden measuring boards with fixed foot-pieces and mobile head-pieces (Gulu District Health Office). For children aged 0-24 months, weight was measured with a mechanical circular dial scale to the nearest $0 \cdot 1 \mathrm{~kg}$ (Seca model 310) and recumbent length was measured with the child lying on a measuring board with an upright headboard and a sliding foot-piece (UNICEF, SO114530, portable baby/child L-hgt mea.syst/SET-2).

In the study we focused on one type of undernutrition as our outcome: underweight. Underweight was chosen because it reflects the current nutritional status in the postconflict setting, whereas stunting reflects chronic malnutrition over a long period and may capture conflict exposures. Additionally, underweight was the most common form of malnutrition across all age groups (Gulu HDSS, unpublished results).

For participants aged $>19$ years, underweight was classified using the WHO cut-off for BMI of $<18.5 \mathrm{~kg} / \mathrm{m}^{2}$. For individuals aged 0-19 years, the WHO AnthroPlus software $^{(31)}$ was used to generate $Z$-scores for anthropometric indices. Underweight was defined as BMI-for-age below $-2 \mathrm{SD}$ of the median BMI-for-age of the National Center for Health Statistics (NCHS)/WHO reference population for individuals aged 5-19 years and as weightfor-age below -2 SD of the median weight-for-age of the WHO growth standards for individuals aged $<5$ years. We excluded pregnant women ( $n$ 296), individuals with missing/implausible values $(<-5 \mathrm{SD}$ and $>5 \mathrm{SD})$ in anthropometric measurements ( $n$ 95), physically disabled ( $n$ 47), drunken individuals ( $n$ 2) and one dwarf. The study sample consisted of 11312 individuals.

\section{Housebold-level variables}

Household and household memberships were defined according to the criteria of the INDEPTH Network ${ }^{(32)}$. Household size was included as a categorical variable, with the average household size of seven members as the reference group. Gender of household head and polygamy were included as binary variables. Child crowding, defined as the number of children $<5$ years of age per room in the household, was included as a binary variable, with $0-1$ child/room as the reference group. We also constructed a child-to-adult ratio as the number of children 
( $<15$ years of age) to the number of adults in the household. SES was assessed based on principal component analysis $^{(33)}$ as most of the study population are subsistence farmers with no stable income. For the SES variable we used the first component with the eigenvalue of 1.91309, with the following information on household assets and living standards (corresponding loading values): type of housing $(0 \cdot 1390)$, water source $(0.2085)$, type of garbage disposal $(0.2027)$, ownership of farm land (-0.0448), livestock (0.0175), domestic animals (0.3576), cattle (0.3400), households assets (kerosene lamp, bicycle, phone, charcoal stove, watch and radio) (0.5312), member of a community savings group (0.3196) and had a bank account (0.4089) (see online supplementary material, Supplemental Table 1).

We included two variables for the nutritional status of the household: (i) living with an adult member who was overweight, coded as 1 if at least one adult person ( $>19$ years) in the household was overweight (BMI $\geq 25 \cdot 0 \mathrm{~kg} / \mathrm{m}^{2}$ ); and (ii) living with a person who was stunted, coded as 1 if at least one person in the household was stunted (length/height-for-age $<-2 \mathrm{sD}$ ), besides the participant him/herself. Stunting was defined as being below $-2 \mathrm{SD}$ of the median height-for-age of the NCHS/ WHO reference population for individuals aged 5-19 years and as being below $-2 \mathrm{SD}$ of the median length/ height-for-age of the WHO growth standards for individuals aged $<5$ years. For stunting among adults (short stature), values of the NCHS/WHO reference population for 19 years of age were applied with the same cut-off (height-forage $<-2 \mathrm{SD}$ ). Deprived area was defined as extremely remote areas in terms of distance and/or poor accessibility. Such areas were identified by qualitative focus group discussions with local field assistants. When the deprived areas had been identified, households were coded to be in a deprived area or a non-deprived area using household identification numbers and their GPS (Global Positioning System) coordinates, which were available from the HDSs system. Lastly, we included distance to the nearest health centre (in kilometres), calculated using $\operatorname{ArcGIS}^{\circledR}$ version 10.3 software by Esri, as a straight line from households to the nearest health centre using GPS coordinates.

\section{Covariates}

Age in years was calculated from date of birth to the date of interview. If no official documentation of date of birth was available, self-reported age would be obtained. A historical event calendar with both national and local events and landmarks was used to estimate age. Season was included as a binary variable, where 1 represented individuals who were measured during the 'hungry season' (May-July) ${ }^{(12)}$.

\section{Statistical analysis}

Characteristics of the study population were summarized using descriptive statistics: medians and interquartile ranges for skewed continuous variables, and frequencies and percentages for categorical variables. Given that all household members were included in the study, the nutritional status was not statistically independent. Therefore, we used multilevel logistic regression models with random effects and unstructured covariance. In addition, polygamy is common in northern Uganda and seventy-one male participants headed and lived in more than one household. Information for these seventy-one men was collected in the field once, but included in the data set for all households that they were registered in (available from the Gulu HDSS). To account for the seventy-one men appearing more than once in the analytical sample, we used four-level multilevel logistic regression models, adding the individual identification numbers (observations) as a cluster for males. Hence, observations represented level 1 ( $n$ 11388), individuals represented level 2 ( $n$ 11312), households represented level 3 ( $n$ 2799) and villages represented level 4 ( $n$ 66). An intercept-only model was used to estimate intraclass correlation coefficients to assess the degree of correlation between individuals in the same household and the same village.

Crude and adjusted multilevel models examined associations between household-level characteristics and underweight. Model 1 included the variables household size, gender of household head, polygamy, child-to-adult ratio, living with someone who was stunted, living with someone who was overweight, deprived area, age and hungry season.

Due to high numbers of missing values for SES (37.0\%), child crowding $(31.1 \%)$ and distance to the nearest health centre $(23.0 \%)$, it was not possible to perform imputations including these variables. Consequently, model 2 included complete cases only ( $n$ 6188), to include these variables in addition to variables in model 1 . We examined statistical significance of the interaction between household-level variables and gender, as well as household-level variables and age. The $P$ value for the interaction term tested for statistical significance of multiplicative interaction. A twosided $\alpha$ level of 0.05 was applied for statistical significance and 0.1 for marginal significance. All analyses were performed using the statistical software package Stata version 14 (2015).

\section{Results}

Overall, $54.3 \%$ of the participants were girls/women and median age was 12.7 (interquartile range $5 \cdot 7-30 \cdot 0$ ) years. In an average household, $17 \cdot 6 \%$ of members were $<5$ years old and $46 \cdot 2 \%$ members were $<15$ years old. Fourteen per cent of the participants lived in polygamous households, $20.9 \%$ in female-headed households and $13 \cdot 3 \%$ in deprived areas (Table 1 ). Overall, more boys/ men than girls/women were underweight (16.9 v. $13 \cdot 9 \%$, 
respectively, $P<0.01$ ). The prevalence of underweight also differed by age group. For boys/men and girls/ women respectively, the prevalence of underweight was $16.6 v .15 \cdot 8 \%$ among children aged $<5$ years $(P>0.05)$; 11.2 v. $9.7 \%$ among children aged $5-12$ years $(P>0.05)$; $16 \cdot 1$ v. $8 \cdot 6 \%$ among adolescents aged 13-19 years $(P<0.05)$; and $23.3 v .18 .3 \%$ among adults aged $\geq 20$ years $(P<0.05$; Fig. 1$)$. The overall intraclass correlation coefficient for level 3 (household) was 0.195 and for level 4

Table 1 Individual and household-level characteristics of the study participants ( $n$ 11312), former internally displaced persons living in a rural post-conflict area of northern Uganda, 2011-2013

\begin{tabular}{|c|c|c|c|}
\hline & $n$ & & $\%$ \\
\hline \multicolumn{4}{|l|}{ Age (years) } \\
\hline Median & \multirow{2}{*}{\multicolumn{3}{|c|}{$\begin{array}{c}12 \cdot 7 \\
5 \cdot 7-30\end{array}$}} \\
\hline IQR & & & \\
\hline $0-4$ & 2539 & & $22 \cdot 5$ \\
\hline $5-12$ & 3196 & & $28 \cdot 3$ \\
\hline $13-19$ & 1539 & & $13 \cdot 6$ \\
\hline$\geq 20$ & 4038 & & $35 \cdot 7$ \\
\hline Underweightł & 1759 & & $15 \cdot 6$ \\
\hline \multicolumn{4}{|l|}{ Headship } \\
\hline Male & 8951 & & $79 \cdot 1$ \\
\hline Female & 2361 & & $20 \cdot 9$ \\
\hline Polygamous household & 1587 & & $14 \cdot 0$ \\
\hline \multicolumn{4}{|l|}{ Household size } \\
\hline Median & \multirow{2}{*}{\multicolumn{3}{|c|}{$\begin{array}{l}7.0 \\
5-8\end{array}$}} \\
\hline IQR & & & \\
\hline 1 member & 229 & & $2 \cdot 0$ \\
\hline 2-4 members & 2374 & & $21 \cdot 0$ \\
\hline 5-6 members & 2972 & & $26 \cdot 3$ \\
\hline 7 members & 1646 & & 14.5 \\
\hline 8-9 members & 2453 & & $21 \cdot 7$ \\
\hline 10-18 members & 1638 & & 14.5 \\
\hline \multicolumn{4}{|l|}{ Child-to-adult ratio } \\
\hline Median & \multirow{2}{*}{\multicolumn{3}{|c|}{$\begin{array}{c}0.5 \\
0.2-1.0\end{array}$}} \\
\hline IQR & & & \\
\hline \multicolumn{4}{|l|}{ Child crowding§ } \\
\hline $0-1 \mathrm{child} / \mathrm{room}$ & 6607 & & 84.8 \\
\hline$>1$ children/room & 1185 & & $15 \cdot 2$ \\
\hline Living with $\geq 1$ stunted person & 4577 & & $40 \cdot 5$ \\
\hline Living with $\geq 1$ overweight person & 1062 & & 9.4 \\
\hline Living in deprived areas $\|$ & 1500 & & $13 \cdot 3$ \\
\hline \multicolumn{4}{|l|}{ Distance $(\mathrm{km})$ to health centre $\mathbb{1}$} \\
\hline Median & \multirow{2}{*}{\multicolumn{3}{|c|}{$\begin{array}{c}2.8 \\
1.8-3.9\end{array}$}} \\
\hline IQR & & & \\
\hline \multicolumn{4}{|l|}{ Household SES** } \\
\hline 1 (lowest quartile) & 1072 & & $15 \cdot 0$ \\
\hline 2 & 1338 & & $18 \cdot 8$ \\
\hline 3 & 1558 & & 21.9 \\
\hline 4 & 1478 & & $20 \cdot 7$ \\
\hline 5 (highest quartile) & 1685 & & $23 \cdot 6$ \\
\hline
\end{tabular}

IQR, interquartile range; SES, socio-economic status; NCHS, National Center for Health Statistics.

Median and IQR (25th-75th percentile) are presented for continuous variables not normally distributed. Categorical variables are expressed as absolute frequency $(n)$ and percentage (\%).

Individuals belonging to more than one household are represented once only.

fUnderweight defined as $\mathrm{BMI}<18.5 \mathrm{~kg} / \mathrm{m}^{2}$ for individuals $>19$ years of age, as BMl-for-age below -2 SD of the median BMl-for-age of the NCHS/WHO reference population for individuals aged 5-19 years and as weight-for-age below -2 SD of the median weight-for-age of the WHO reference population for individuals $<5$ years of age.

$\$ 31.1 \%$ ( $n$ 3520) missing values for child crowding.

|l In total, 380 households lived in deprived areas.

\23.0\% ( $n$ 2600) missing values for distance to the nearest health centre.

**37.0\% ( $n$ 4181) missing values for SES. (village) was $0 \cdot 041$. Hence, $\sim 20 \%$ of the residual variance in underweight in this study population could be explained by common household factors and $\sim 4 \%$ by common village-level factors.

Table 2 shows the overall crude and adjusted associations between household-level variables and underweight. In the crude model, living alone or in a small household (2-4 members) was associated with higher odds for underweight compared with living in an average-size household $(\mathrm{OR}=3.53$; $95 \% \mathrm{CI} 2.47,5.06$ and $\mathrm{OR}=1.23$; $95 \%$ CI 0.99, 1.53, respectively). However, after adjustment in model 1 , only living alone remained associated with underweight $(\mathrm{OR}=1 \cdot 64 ; 95 \% \mathrm{CI} 1 \cdot 10,2 \cdot 46$; overall $P>0 \cdot 1$ ). Living in a female-headed $v$. male-headed household was positively associated with underweight in the crude model, but the association fully attenuated in model 1 (OR $=1 \cdot 01 ; 95 \%$ CI 0.86, 1.18). Living in the same household as a person who was stunted and living in a deprived area were positively associated with underweight $(\mathrm{OR}=1 \cdot 19 ; 95 \%$ CI 1.04, 1.36 and OR $=1.37 ; 95 \%$ CI $0.97,1.94 ; P<0 \cdot 1)$. Household factors associated with lower odds of underweight included polygamous $v$. monogamous households (OR $=0.79 ; 95 \%$ CI 0.65, 0.97) and overweight $v$. non-overweight households ( $\mathrm{OR}=0 \cdot 65$; $95 \%$ CI $0.49,0.87$ ). For model 2 (including additional variables with missing observations), increasing distance to the nearest health centre was associated with higher odds for underweight $(\mathrm{OR}=1 \cdot 41-1 \cdot 60)$, although the association attenuated slightly for the highest quartile $(P$-trend $<0 \cdot 05)$. Child crowding was positively associated with underweight $(\mathrm{OR}=1.23 ; 95 \%$ CI $0.96,1.57)$. No association was found between SES and underweight (Table 2).

We found statistically significant interactions between gender and headship, gender and polygamy, age and headship, and age and living with someone who was stunted (all $P<0.05$ ), as well as a marginally significant three-way interaction between headship, gender and age $(P<0 \cdot 1)$. Therefore, we repeated model 1 stratified by gender and age groups (0-4, 5-12, 13-19 and $\geq 20$ years). Tables 3 and 4 show the gender- and age-stratified models for boys/men and girls/women, respectively. In stratified models, higher odds for underweight when living alone were only seen among adult men $(\geq 20$ years: $\mathrm{OR}=3 \cdot 23$; $95 \%$ CI $1 \cdot 22,8 \cdot 59)$. The association between headship and underweight differed across gender and age group: living in a female-headed $v$. male-headed household was associated with statistically significant higher odds of underweight among adult men aged $\geq 20$ years $(\mathrm{OR}=2 \cdot 18 ; 95 \%$ CI $1 \cdot 11,4 \cdot 27)$ and among girls aged $0-4$ years $(O R=1 \cdot 51$; $95 \%$ CI $0.97,2.34)$, and statistically significant lower odds among adolescent women aged 13-19 years $(\mathrm{OR}=0 \cdot 46$; $95 \%$ CI $0.22,0.97)$. Living in a polygamous $v$. monogamous household was associated with statistically significant lower odds for underweight among adult men ( $\geq 20$ years: $\mathrm{OR}=0.46 ; 95 \% \mathrm{CI} 0 \cdot 25,0 \cdot 82$ ) and adolescent 


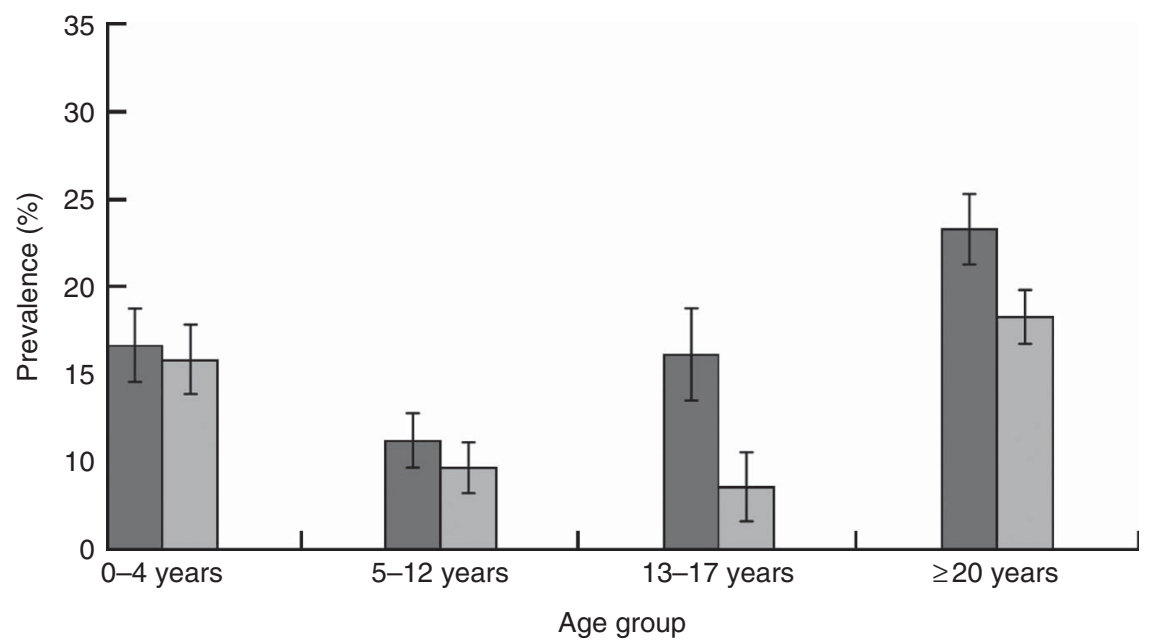

Fig. 1 Prevalence of underweight by age group and gender ( $\square$, boys/men; $\square$, girls/women), with $95 \% \mathrm{Cl}$ represented by vertical bars, among the study participants $(n$ 11312), former internally displaced persons living in a rural post-conflict area of northern Uganda, 2011-2013

women $(13-19$ years: OR=0.44; 95\% CI 0.18, 1.08), but no associations was seen in the other age groups. Girls aged 0-4 years who lived in a household with the highest child-to-adult ratio had lower odds of being underweight compared with their counterparts living in households with the lowest ratio $(\mathrm{OR}=0 \cdot 50 ; 95 \% \mathrm{CI} 0 \cdot 30,0 \cdot 85$; overall $P<0 \cdot 1$; Tables 3 and 4).

\section{Discussion}

In the present study among former internally displaced persons living in a rural post-conflict area of northern Uganda, we found that the associations between household-level factors and underweight differed across gender and age. Living in a female-headed $v$. male-headed household was associated with higher odds for underweight among adult men and girls aged $<5$ years, but lower odds among adolescent women. Living alone, especially among adult men, living in a household with a stunted member, living in a deprived area or further away from a health centre were all associated with higher odds of underweight. In contrast, living in a polygamous household, higher child-to-adult ratio and living in a household with an overweight member were associated with lower odds for underweight.

We are not aware of other studies comparing adult underweight and household headship. However, in a previous study examining individual-level risk factors for adult underweight, divorced men, but not divorced or widowed women, had a higher odds for being underweight $^{(12)}$. This gender discrepancy may be explained by the social changes in northern Uganda described by Dolan as collapsing masculinities and the proliferation of small men ${ }^{(28)}$, which may apply particularly to men living in female-headed households. Further adjustment of previously identified individual-level risk factors for underweight (marital status, alcohol, smoking) ${ }^{(12)}$ did not change the estimates in the present study (data not shown). Findings from previous studies among children aged $<5$ years have been inconsistent; a study from Ethiopia supports our finding of a higher prevalence of childhood underweight among female-headed households $^{(25)}$. However, in Kenya no difference in childhood underweight according to headship was found ${ }^{(26)}$. Both studies used small study samples $(n<200)$ and no statistical tests with adjustment for confounding factors were performed $^{(25,26)}$. Shell-Duncan and Obungu Obiero ${ }^{(34)}$ found interaction between headship and SES in Kenya, whereby children of poor female-headed households had a higher risk of undernutrition (measured by wasting and stunting), but children of economically sufficient femaleheaded households had a lower risk of undernutrition, compared with children in male-headed households in general. We did not find such an interaction (data not shown). Instead, the discrepancy may be explained by differences in the nature of female-headed households, age of the household head and cultural practices. In Kenya $^{(26,34)}$ female headship was mainly due to migrant labour of the husband who may still support the household economically, whereas in our study setting women of female headship had the main provider responsibility. We conducted further descriptive analyses and found that individuals living in female-headed households were on average older, $40 \%$ were widows, more girls/women than boys/men lived in female-headed households, the households were smaller in size, fewer lived in deprived areas, there was less child crowding, household stunting and overweight, and the female-headed households had lower SES (see online supplementary material, Supplemental Table 2).

In contrast to our findings, a qualitative study from another area of Uganda reported polygamy to be an important risk factor for childhood malnutrition ${ }^{(24)}$. 
Table 2 Associations between household-level characteristics and underweight by multilevel logistic regression among all study participants ( $n$ 11388), former internally displaced persons living in a rural post-conflict area of northern Uganda, 2011-2013

\begin{tabular}{|c|c|c|c|c|c|c|}
\hline & \multicolumn{2}{|c|}{ Crude (n 11388) } & \multicolumn{2}{|c|}{ Model 1 ( $n$ 11388) } & \multicolumn{2}{|c|}{ Model 2 ( $n$ 6188) } \\
\hline & OR & $95 \% \mathrm{Cl}$ & Adjusted OR & $95 \% \mathrm{Cl}$ & Adjusted OR & $95 \% \mathrm{Cl}$ \\
\hline \multicolumn{7}{|l|}{ Headship } \\
\hline Male & 1.00 & Ref. & 1.00 & Ref. & 1.00 & Ref. \\
\hline Female & 1.22 & $1.05,1.42 \dagger$ & 1.01 & $0.86,1.18$ & 0.89 & $0.71,1.11$ \\
\hline \multicolumn{7}{|l|}{ Polygamy } \\
\hline No & 1.00 & Ref. & 1.00 & Ref. & 1.00 & Ref. \\
\hline Yes & 0.74 & $0.60,0.90 \dagger$ & 0.79 & $0.65,0.97 \dagger$ & 0.84 & $0.65,1.08$ \\
\hline \multicolumn{7}{|l|}{ Household size (members) } \\
\hline 7 members & 1.00 & Ref. & 1.00 & Ref. & 1.00 & Ref. \\
\hline 1 member & 3.53 & $2.47,5.06$ & 1.64 & $1 \cdot 10,2.46$ & 1.38 & $0.78,2.44$ \\
\hline 2-4 members & 1.23 & $0.99,1.53$ & 0.98 & $0.76,1.26$ & 0.85 & $0.61,1.19$ \\
\hline 5-6 members & 1.01 & $0.82,1.25$ & 0.93 & $0.74,1.17$ & 0.85 & $0.63,1.15$ \\
\hline 8-9 members & 0.94 & $0.75,1.18$ & 0.90 & $0.72,1.14$ & 0.87 & $0.64,1.17$ \\
\hline 10-18 members & 1.04 & $0.80,1.35 \dagger$ & 0.99 & $0.76,1.28$ & 0.91 & $0.66,1.26$ \\
\hline \multicolumn{7}{|l|}{ Child-to-adult ratio } \\
\hline 1 (lowest, ratio $=0.1)$ & 1.00 & Ref. & 1.00 & Ref. & 1.00 & Ref. \\
\hline 2 (second lowest, ratio $=1.1-1.5$ ) & 0.77 & $0.64,0.92$ & 0.98 & $0.80,1.21$ & 0.90 & $0.69,1.17$ \\
\hline 3 (second highest, ratio $=1 \cdot 6-2$ ) & 0.80 & $0.67,0.95$ & 1.05 & $0.86,1.28$ & 1.00 & $0.77,1.29$ \\
\hline 4 (highest, ratio $=2 \cdot 25-7$ ) & 0.68 & $0.58,0.81 \dagger$ & 0.91 & $0.74,1.11$ & 0.87 & $0.67,1.12$ \\
\hline \multicolumn{7}{|l|}{ Child crowding } \\
\hline $0-1$ child/room & 1.00 & Ref. & & & 1.00 & Ref. \\
\hline$>1$ child/room & 1.09 & $0.87,1.36$ & & & 1.23 & $0.96,1.57^{*}$ \\
\hline \multicolumn{7}{|l|}{ Living with $\geq 1$ stunted person } \\
\hline No & 1.00 & Ref. & 1.00 & Ref. & 1.00 & Ref. \\
\hline Yes & 1.03 & $0.90,1.17$ & 1.19 & $1.04,1.36 \dagger$ & 1.21 & $1.01,1.45 \dagger$ \\
\hline \multicolumn{7}{|l|}{ Living with $\geq 1$ overweight person } \\
\hline No & 1.00 & Ref. & 1.00 & Ref. & 1.00 & Ref. \\
\hline Yes & 0.56 & $0.42,0.75 \dagger$ & 0.65 & $0.49,0.87 \dagger$ & 0.63 & $0.43,0.93 \dagger$ \\
\hline \multicolumn{7}{|l|}{ Deprived area } \\
\hline No & 1.00 & Ref. & 1.00 & Ref. & 1.00 & Ref. \\
\hline Yes & 1.28 & $0.90,1.83$ & 1.37 & $0.97,1.94^{\star}$ & 1.51 & $0.93,2.45^{\star}$ \\
\hline \multicolumn{7}{|l|}{ Distance to health centre } \\
\hline 1 (lowest quartile, $0.05-1.8 \mathrm{~km}$ ) & 1.00 & Ref. & & & 1.00 & Ref. \\
\hline $2(1.9-2.7 \mathrm{~km})$ & 1.26 & $0.95,1.67$ & & & 1.41 & $1.03,1.94$ \\
\hline $3(2.8-3.9 \mathrm{~km})$ & 1.46 & $1.08,1.97$ & & & 1.60 & $1 \cdot 13,2.27$ \\
\hline 4 (highest quartile, $4.0-9.9 \mathrm{~km}$ ) & 1.21 & $0.87,1.68^{\star}$ & & & 1.42 & $0.98,2.06 \dagger$ \\
\hline \multicolumn{7}{|l|}{ Household SES } \\
\hline 1 (lowest quartile) & 1.00 & Ref. & & & 1.00 & Ref. \\
\hline 2 & 0.85 & $0.65,1.12$ & & & 0.98 & $0.73,1.30$ \\
\hline 3 & 0.83 & $0.64,1.09$ & & & 1.05 & $0.79,1.39$ \\
\hline 4 & 0.82 & $0.63,1.08$ & & & 1.09 & $0.81,1.45$ \\
\hline 5 (highest quartile) & 0.73 & $0.55,0.95$ & & & 0.94 & $0.69,1.27$ \\
\hline
\end{tabular}

$n$, number of observations (individuals included in each model); SES, socio-economic status; Ref., reference category.

OR and corresponding $95 \% \mathrm{Cl}$ presented by four-level multilevel logistic regression models, where level 1 represents observations, level 2 represents individuals, level 3 represents households and level 4 represents villages.

Model 1 adjusted for age, sex, season when the anthropometric measurements were taken, sex of household head, polygamy, household size, child-to-adult ratio, living with $\geq 1$ stunted person, living with $\geq 1$ overweight person and deprived area.

Model 2 adjusted for age, sex, season when the anthropometric measurements were taken, sex of household head, polygamy, household size, child-to-adult ratio, living with $\geq 1$ stunted person, living with $\geq 1$ overweight person, deprived area, child crowding, distance to health centre and household SES.

Entries in bold mark statistically significant associations. Significance level: ${ }^{\star} P<0.10$ and $\dagger P<0.05$ by testparm (Stata version 14 ).

Dilution of resources was hypothesized as the cause for the negative impact of polygamy on nutritional status ${ }^{(23,24)}$. In line with our findings, previous quantitative studies from other sub-Saharan African countries found no association between polygamy and underweight among children $^{(21,23,34,35)}$. In northern Uganda, polygamy is likely to be a sign of wealth, due to bridal price and increased financial responsibilities for men with more wives ${ }^{(24)}$. However, this explanation is not supported by an association between SES and underweight in the present study. Instead, it may be that social capital is a stronger predictor for nutritional status than SES, which has been found in studies with child mortality in Ethiopia ${ }^{(36)}$ and GuineaBissau $^{(37)}$. In Uganda, households are key units where resources are pooled together and connected to wider networks ${ }^{(29,38)}$. Social capital and social networks may contribute to improved health and nutritional status by sharing household responsibilities, including food/cooking and caring for children, greater trust and ability to borrow money in case of emergencies, as well as providing/ accessing information, advice and guidance ${ }^{(29,38,39)}$. Thus, small households and living in deprived areas may be a marker for low social capital, whereas polygamy and a high child-to-adult ratio may be markers for high social capital. 
Table 3 Age-stratified associations between household-level characteristics and underweight by multilevel logistic regression among boys and men ( $n$ 5248), former internally displaced persons living in a rural post-conflict area of northern Uganda, 2011-2013

\begin{tabular}{|c|c|c|c|c|c|c|c|c|}
\hline & \multicolumn{2}{|c|}{ Age $0-4$ years $(n 1226)$} & \multicolumn{2}{|c|}{ Age $5-12$ years $(n 1580)$} & \multicolumn{2}{|c|}{ Age $13-19$ years $(n 757)$} & \multicolumn{2}{|c|}{ Age $\geq 20$ years $(n 1685)$} \\
\hline & OR & $95 \% \mathrm{Cl}$ & OR & $95 \% \mathrm{Cl}$ & OR & $95 \% \mathrm{Cl}$ & OR & $95 \% \mathrm{Cl}$ \\
\hline \multicolumn{9}{|l|}{ Headship } \\
\hline Male & 1.00 & Ref. & 1.00 & Ref. & 1.00 & Ref. & 1.00 & Ref. \\
\hline Female & 1.37 & $0.87,2.15$ & 0.79 & $0.44,1.42$ & 1.29 & $0.74,2.24$ & $2 \cdot 18$ & $1.11,4.27 \dagger$ \\
\hline \multicolumn{9}{|l|}{ Polygamy } \\
\hline No & 1.00 & Ref. & 1.00 & Ref. & 1.00 & Ref. & 1.00 & Ref. \\
\hline Yes & 1.07 & $0.68,1.69$ & 0.80 & $0.43,1.51$ & 0.68 & $0.37,1.26$ & 0.46 & $0.25,0.82 \dagger$ \\
\hline \multicolumn{9}{|l|}{ Household size } \\
\hline 7 members & 1.00 & Ref. & 1.00 & Ref. & 1.00 & Ref. & 1.00 & Ref. \\
\hline 1 member & - & - & - & - & - & - & 3.23 & $1.22,8.59$ \\
\hline 2-4 members & 1.57 & $0.80,3.08$ & 0.93 & $0.38,2.27$ & 0.86 & $0.34,2.18$ & 1.31 & $0.65,2.66$ \\
\hline 5-6 members & $1 \cdot 31$ & $0.72,2.38$ & 0.79 & $0.39,1.58$ & 0.90 & $0.41,1.97$ & 1.50 & $0.76,2.96$ \\
\hline 8-9 members & 1.17 & $0.64,2.15$ & 0.91 & $0.47,1.78$ & $1 \cdot 12$ & $0.54,2.32$ & 1.21 & $0.61,2.38$ \\
\hline 10-18 members & 1.77 & $0.94,3.33$ & $1 \cdot 14$ & $0.54,2.40$ & 0.65 & $0.28,1.49$ & 1.03 & $0.49,2.17$ \\
\hline \multicolumn{9}{|l|}{ Child-to-adult ratio } \\
\hline 1 (lowest, ratio $=0.1)$ & 1.00 & Ref. & 1.00 & Ref. & 1.00 & Ref. & 1.00 & Ref. \\
\hline 2 (second lowest, ratio $=1 \cdot 1-1 \cdot 5)$ & 0.68 & $0.38,1.22$ & 0.68 & $0.34,1.37$ & 0.95 & $0.50,1.81$ & 1.02 & $0.59,1.77$ \\
\hline 3 (second highest, ratio $=1.6-2$ ) & 1.00 & $0.60,1.67$ & 1.90 & $0.47,1.71$ & 1.57 & $0.83,2.97$ & 1.01 & $0.58,1.77$ \\
\hline 4 (highest, ratio $=2 \cdot 25-7$ ) & 0.89 & $0.53,1.50$ & 1.93 & $0.60,1.42$ & 1.47 & $0.83,2.90$ & 1.03 & $0.55,1.93$ \\
\hline \multicolumn{9}{|l|}{ Living with $\geq 1$ stunted person } \\
\hline No & 1.00 & Ref. & 1.00 & Ref. & 1.00 & Ref. & 1.00 & Ref. \\
\hline Yes & 1.62 & $1 \cdot 16,2 \cdot 26 \dagger$ & 0.92 & $0.60,1.42$ & 1.86 & $1.17,2.98 \dagger$ & 1.38 & $0.93,2.04$ \\
\hline \multicolumn{9}{|l|}{ Living with $\geq 1$ overweight person } \\
\hline No & 1.00 & Ref. & 1.00 & Ref. & 1.00 & Ref. & 1.00 & Ref. \\
\hline Yes & 0.34 & $0.16,0.75 \dagger$ & 0.35 & $0.14,0.86 \dagger$ & $0 \cdot 70$ & $0.31,1.59$ & 0.55 & $0.27,1 \cdot 11^{*}$ \\
\hline \multicolumn{9}{|l|}{ Deprived area } \\
\hline No & 1.00 & Ref. & 1.00 & Ref. & 1.00 & Ref. & 1.00 & Ref. \\
\hline Yes & $1 \cdot 16$ & $0.68,1.96$ & 1.79 & $0.87,3.72$ & 0.87 & $0.34,2.21$ & 1.54 & $0.79,3.00$ \\
\hline
\end{tabular}

$n$, number of observations (individuals included in each model); SES, socio-economic status; Ref., reference category.

OR and corresponding $95 \% \mathrm{Cl}$ are presented by four-level multilevel logistic regression models, where level 1 represents observations, level 2 represents individuals, level 3 represents households and level 4 represents villages.

All OR adjusted for age, sex, season when the anthropometric measurements were taken, sex of household head, polygamy, household size, child-to-adult ratio, living with $\geq 1$ stunted person, living with $\geq 1$ overweight person and deprived area.

Entries in bold mark statistically significant associations. Significance level: ${ }^{*} P<0.10$ and $\dagger P<0.05$ by testparm (Stata version 14 ).

Adelman found that increasing social network size, particularly membership of farmers' groups, was significantly positively associated with increased height-for-age $Z$-score among children in internally displaced persons' camps during the insurgency in Uganda ${ }^{(29)}$. In line with our findings, Adelman ${ }^{(29)}$ and Johnecheck and Holland ${ }^{(17)}$ also reported no variation in child height-for-age $Z$-score by SES.

We found a positive association between deprived areas and underweight. Likewise, increasing odds for underweight were seen with increasing distance to the nearest health centre. This is in line with a previous study from south-west Uganda ${ }^{(27)}$. Yet, the question of whether poor and unhealthier people live in deprived areas or living in a deprived area causes underweight is unanswered. Still these findings indicate that even in this postconflict rural area there are geographical variations in underweight, which needs further investigation.

\section{Strengths and limitations}

To our knowledge, the current study is the first examining associations between nutritional status and householdlevel factors among all age groups in the same population.
Additionally, these associations have not previously been investigated in post-conflict settings. The application of the multilevel models is a strength compared with previous studies examining household factors. It is plausible that unmeasured confounders confused the observed associations. Potential unmeasured confounders could be HIV/ AIDS or other disease. The estimated HIV prevalence in 2011 for mid-northern Uganda was 10.1\% among women and $6.3 \%$ among men ${ }^{(40)}$. HIV is highly stigmatized in northern Uganda, thus it was not possible to obtain reliable information without compromising the communitybased study design ${ }^{(12)}$. Educational attainment of mothers and household heads has been found to mitigate malnutrition issues in various settings ${ }^{(41)}$. We did not include information on education since it was highly correlated with age because universal primary education was not introduced in Uganda until 1997. A major limitation of the study is the high numbers of missing values for SES, child crowding and distance to health centre. The high number of missing data is due to data being collected at different time points. We assumed data were missing at random (not dependent on SES itself). However, we found significant differences in the outcome variable and household-level factors between observations with 
Table 4 Age-stratified associations between household-level characteristics and underweight by multilevel logistic regression among girls and women $(n 6140)$, former internally displaced persons living in a rural post-conflict area of northern Uganda, 2011-2013

\begin{tabular}{|c|c|c|c|c|c|c|c|c|}
\hline & \multicolumn{2}{|c|}{ Age $0-4$ years $(n 1314)$} & \multicolumn{2}{|c|}{ Age $5-12$ years $(n 1616)$} & \multicolumn{2}{|c|}{ Age $13-19$ years $(n 782)$} & \multicolumn{2}{|c|}{ Age $\geq 20$ years $(n 2428)$} \\
\hline & OR & $95 \% \mathrm{Cl}$ & OR & $95 \% \mathrm{Cl}$ & OR & $95 \% \mathrm{Cl}$ & OR & $95 \% \mathrm{Cl}$ \\
\hline \multicolumn{9}{|l|}{ Headship } \\
\hline Male & 1.00 & Ref. & 1.00 & Ref. & 1.00 & Ref. & 1.00 & Ref. \\
\hline Female & 1.51 & $0.97,2.34^{\star}$ & 1.30 & $0 \cdot 76,2 \cdot 22$ & 0.46 & $0.22,0.97 \dagger$ & 1.20 & $0.89,1.61$ \\
\hline \multicolumn{9}{|l|}{ Polygamy } \\
\hline No & 1.00 & Ref. & 1.00 & Ref. & 1.00 & Ref. & 1.00 & Ref. \\
\hline Yes & 0.86 & $0.53,1.40$ & 0.69 & $0.37,1.30$ & 0.44 & $0.18,1.08^{\star}$ & 0.90 & $0.61,1.33$ \\
\hline \multicolumn{9}{|l|}{ Household size (members) } \\
\hline 7 members & 1.00 & Ref. & 1.00 & Ref. & 1.00 & Ref. & 1.00 & Ref. \\
\hline 1 member & - & - & - & - & - & - & 1.36 & $0.71,2 \cdot 61$ \\
\hline 2-4 members & 0.57 & $0.29,1.12$ & 0.86 & $0.37,1.97$ & 0.60 & $0.21,1.73$ & 1.02 & $0.64,1.63$ \\
\hline 5-6 members & 0.90 & $0.51,1.58$ & 0.63 & $0.32,1.24$ & 0.76 & $0.30,1.93$ & 0.91 & $0.58,1.41$ \\
\hline $8-9$ members & 0.89 & $0.50,1.56$ & 0.79 & $0.41,1.51$ & 0.49 & $0.19,1.21$ & 0.80 & $0.49,1.30$ \\
\hline 10-18 members & 0.78 & $0.42,1.44$ & 0.69 & $0.33,1.44$ & 0.84 & $0.36,1.91$ & 1.02 & $0.61,1.72$ \\
\hline \multicolumn{9}{|l|}{ Child-to-adult ratio } \\
\hline 1 (lowest, ratio $=0.1)$ & 1.00 & Ref. & 1.00 & Ref. & 1.00 & Ref. & 1.00 & Ref. \\
\hline 2 (second lowest, ratio $=1 \cdot 1-1.5)$ & 0.65 & $0.38,1.10$ & 1.34 & $0.68,2.65$ & 1.33 & $0.62,2.85$ & 1.21 & $0.82,1.78$ \\
\hline 3 (second highest, ratio $=1 \cdot 6-2$ ) & 0.82 & $0.50,1.36$ & 0.85 & $0.44,1.66$ & 0.89 & $0.38,2.07$ & 1.19 & $0.83,1.73$ \\
\hline 4 (highest, ratio $=2 \cdot 25-7$ ) & 0.50 & $0.30,0.85^{\star}$ & 0.92 & $0.50,1.70$ & $1 \cdot 18$ & $0.52,2.69$ & 0.79 & $0.53,1.18$ \\
\hline \multicolumn{9}{|l|}{ Living with $\geq 1$ stunted person } \\
\hline No & 1.00 & Ref. & 1.00 & Ref. & 1.00 & Ref. & 1.00 & Ref. \\
\hline Yes & 2.01 & $1.45,2.80 \dagger$ & 1.49 & $0.97,2 \cdot 28^{\star}$ & 1.26 & $0.72,2 \cdot 19$ & 1.07 & $0.83,1.40$ \\
\hline \multicolumn{9}{|l|}{ Living with $\geq 1$ overweight person } \\
\hline No & 1.00 & Ref. & 1.00 & Ref. & 1.00 & Ref. & 1.00 & Ref. \\
\hline Yes & 0.58 & $0.28,1.20$ & 0.27 & $0.10,0.77 \dagger$ & 0.53 & $0.18,1.56$ & 0.65 & $0.28,1.55$ \\
\hline \multicolumn{9}{|l|}{ Deprived area } \\
\hline No & 1.00 & Ref. & 1.00 & Ref. & 1.00 & Ref. & 1.00 & Ref. \\
\hline Yes & 1.66 & $0.97,2.82^{*}$ & $1 \cdot 14$ & $0.54,2.42$ & 1.55 & $0.66,3.66$ & 1.38 & $0.87,2 \cdot 22$ \\
\hline
\end{tabular}

$n$, number of observations (individuals included in each model); SES, socio-economic status; Ref., reference category.

OR and corresponding $95 \% \mathrm{Cl}$ are presented by four-level multilevel logistic regression models, where level 1 represents observations, level 2 represents individuals, level 3 represents households and level 4 represents villages.

All OR adjusted for age, sex, season when the anthropometric measurements were taken, sex of household head, polygamy, household size, child-to-adult ratio, living with $\geq 1$ stunted person, living with $\geq 1$ overweight person and deprived area.

Entries in bold mark statistically significant associations. Significance level: ${ }^{\star} P<0.10$ and $\dagger P<0.05$ by testparm (Stata version 14 ).

missing and with complete information (see online supplementary material, Supplemental Table 3). This may explain why the estimates in models 1 and 2 (Table 2) are different. Finally, the study's conclusions may be limited to post-conflict populations with similar socio-economic and cultural characteristics where the gender roles are similar.

\section{Conclusion}

In summary, we found gender- and age-specific associations between household-level factors and underweight. Associations between household-level characteristics and underweight are likely to reflect local social capital structures. International and local organizations should understand and adapt to these local social capital structures before implementing conventional health and nutritional interventions.

\section{Acknowledgements}

Acknowledgements: The authors are very grateful to all residents in Awach for their willingness to participate in the study and the Gulu HDSS field assistants for their determined hard work. The authors wish to thank: the Gulu District Health Office for its overall support and collaboration; the data management team at the Postconflict Primary Health Care project at Gulu University and the team of the ENRECA project; Siri Aas Smedemark for her assistance in field supervision and data cleaning; and Professor Nadine Schuurman and her students Rebecca Gunderson and Kendra Munn from the Simon Fraser University for assisting with the spatial data calculations. Financial support: The study was supported by DANIDA (DFC project codes 54-08-AAU and 12-057-SDU), DANIDA Fellowship Centre (S.S., grant number R272-A14195) and the Lundbeck Foundation (S.S. and M.S., grant number R94-A7993). The Gulu District Health Office in Uganda supported the study by supplying wooden measuring boards for children and adults. DANIDA, the Lundbeck Foundation and the Gulu District Health Office had no role in the design, analysis or writing of this article. Conflict of interest: None. Authorship: S.S., J.N., F.O.K. and M.S. formulated the research question. S.S., F.O.K., E.O. and M.S. designed and initiated the study. S.S., C.L.O. and F.O.K. trained field assistants and supervised data collection. S.S. and C.L.O. performed data cleaning and data management procedures. S.S., J.N. and M.S. analysed the 
data. S.S. and J.N. wrote the article with major contributions from F.O.K, C.L.O., E.O. and M.S. All authors reviewed and approved the manuscript. Ethics of human subject participation: This study was conducted according to the guidelines laid down in the Declaration of Helsinki and all procedures involving human subjects were approved by the Research and Ethics Committees of Gulu University and the Uganda National Council for Science and Technology (reference SS 2363). Written informed consent was obtained from all subjects and additional written consent was obtained from caregivers for participants aged $<18$ years.

\section{Supplementary material}

To view supplementary material for this article, please visit https://doi.org/10.1017/S1368980018001581

\section{References}

1. United Nations High Commissioner for Refugees (2016) Global Trends. Forced Displacement in 2016. http://www. unhcr.org/statistics/unhcrstats/5943e8a34/global-trendsforced-displacement-2016.html (accessed September 2017).

2. Young H, Borrel A, Holland D et al. (2004) Public nutrition in complex emergencies. Lancet 364, 1899-1909.

3. Salama P, Spiegel P, Talley L et al. (2004) Lessons learned from complex emergencies over past decade. Lancet 364 , 1801-1813.

4. Andresen E, Bilukha OO, Menkir Z et al. (2014) Notes from the field: Malnutrition and elevated mortality among refugees from South Sudan - Ethiopia, June-July 2014. $M M W R$ Morb Mortal Wkly Rep 63, 700-701.

5. Feikin DR, Adazu K, Obor D et al. (2010) Mortality and health among internally displaced persons in western Kenya following post-election violence, 2008: novel use of demographic surveillance. Bull World Health Organ $\mathbf{8 8}$, 601-608.

6. Devakumar D, Birch M, Osrin D et al. (2014) The intergenerational effects of war on the health of children. $B M C$ Med 12, 57.

7. Whyte SR, Babiiha S, Mukyala R et al. (2014) Urbanisation by subtraction: the afterlife of camps in northern Uganda. J Mod Afr Stud 52, 597-622.

8. Internal Displacement Monitoring Centre (2010) Uganda: Difficulties continue for returnees and remaining IDPs as development phase begins. A profile of the internal displacement situation. http://www.internal-displacement.org/ assets/library/Africa/Uganda/pdf/Uganda-December-2010. pdf (accessed September 2017).

9. Food and Agricultural Organization of the United Nations (2010) Integrated Food Security Phase Classification. Uganda Food Security Brief. Special Brief - Post Second Season 2009 Analysis. http://www.fao.org/fileadmin/user_upload/drought/ docs/Uganda\%20IPC\%20Brief_May2010.pdf (accessed September 2017)

10. Centre for Research on the Epidemiology of Disasters (2013) People affected by conflict 2013. Humanitarian needs in number. http://reliefweb.int/sites/reliefweb.int/files/resour ces/PubID303ConflictReport.pdf (accessed September 2017).

11. Olwedo MA, Mworozi E, Bachou H et al. (2008) Factors associated with malnutrition among children in internally displaced person's camps, northern Uganda. Afr Health Sci 8, 244-252.
12. Schramm S, Kaducu FO, Smedemark SA et al. (2016) Gender and age disparities in adult undernutrition in northern Uganda: high-risk groups not targeted by food aid programmes. Trop Med Int Health 21, 807-817.

13. Colombatti R, Coin A, Bestagini P et al. (2008) A short-term intervention for the treatment of severe malnutrition in a post-conflict country: results of a survey in Guinea Bissau. Public Health Nutr 11, 1357-1364.

14. Ramli Agho KE, Inder KJ et al. (2009) Prevalence and risk factors for stunting and severe stunting among underfives in North Maluku province of Indonesia. $B M C$ Pediatr 9, 64 .

15. Doocy S, Lewy D, Guenther $\mathrm{T}$ et al. (2010) Mortality, nutrition and health in Lofa County Liberia five years postconflict. World Health Popul 12, 23-33.

16. Rossi L, Hoerz T, Thouvenot V et al. (2006) Evaluation of health, nutrition and food security programmes in a complex emergency: the case of Congo as an example of a chronic post-conflict situation. Public Health Nutr 9, 551-556.

17. Johnecheck WA \& Holland DE (2007) Nutritional status in postconflict Afghanistan: evidence from the national surveillance system pilot and national risk and vulnerability assessment. Food Nutr Bull 28, 3-17.

18. Paul A, Doocy S, Tappis H et al. (2014) Preventing malnutrition in post-conflict, food insecure settings: a case study from South Sudan. PLoS Curr 6, doi: 10.1371/currents. dis.54cd85fa3813b0471abc3ebef1038806.

19. Al Gasseer N, Dresden E, Keeney GB et al. (2004) Status of women and infants in complex humanitarian emergencies. J Midwifery Womens Health 49, 4 Suppl. 1, S7-S13.

20. United Nations World Food Programme (2006) Policy Issues. Agenda item 5. Targeting in Emergencies. https:// www.wfp.org/sites/default/files/wfp083629.pdf (accessed September 2017).

21. Sellen DW (1999) Polygyny and child growth in a traditional pastoral society. Hum Nat 10, 329-371.

22. Gillett-Netting R \& Perry A (2005) Gender and nutritional status at the household level among Gwembe Valley Tonga children, 0-10 years. Am J Hum Biol 17, 372-375.

23. Hadley C (2005) Is polygyny a risk factor for poor growth performance among Tanzanian agropastoralists? Am J Phys Anthropol 126, 471-480.

24. Ickes SB, Heymsfield GA, Wright TW et al. (2017) 'Generally the young mom suffers much': socio-cultural influences of maternal capabilities and nutrition care in Uganda. Matern Child Nutr 13, e12365.

25. Haidar J \& Kogi-Makau W (2009) Gender differences in the household-headship and nutritional status of pre-school children. East Afr Med J 86, 69-73.

26. Onyango A, Tucker K \& Eisemon T (1994) Household headship and child nutrition: a case study in western Kenya. Soc Sci Med 39, 1633-1639.

27. Vella V, Tomkins A, Nviku J et al. (1995) Determinants of nutritional status in south-west Uganda. $J$ Trop Pediatr 41, 89-98.

28. Dolan C (2002) Collapsing masculinities and weak states: a case study of Northern Uganda. In Masculinities Matter, pp. 57-83 [F Cleaver, editor]. New York: Zed Books.

29. Adelman $S$ (2008) It takes a farmers' group to raise a child: the impacts of local social networks on child health outcomes in Ugandan internally displaced person's camps. http://paa2009. princeton.edu/papers/90849 (accessed September 2017).

30. Whyte SR, Babiiha SM, Mukyala R et al. (2013) Remaining internally displaced: missing links to security in Northern Uganda. J Refug Stud 26, 283-301.

31. World Health Organization (2009) WHO AnthroPlus for personal computers manual: software for assessing growth of the world's children and adolescents. http://www.who. 
int/growthref/tools/who_anthroplus_manual.pdf?ua=1 (accessed September 2017).

32. International Network for the Demographic Evaluation of Populations and Their Health in Developing Countries (2015) INDEPTH Resource Kit for Demographic Surveillance Systems. Household, membership and residency. http:// www.indepth-network.org/resources/indepth-resource-kit-0 (accessed June 2018).

33. Vyas S \& Kumaranayake L (2006) Constructing socioeconomic status indices: how to use principal components analysis. Health Policy Plan 21, 459-468.

34. Shell-Duncan B \& Obungu Obiero W (2000) Child nutrition in the transition from nomadic pastoralism to settled lifestyles: individual, household, and community-level factors. Am J Phys Anthropol 113, 183-200.

35. Lawson DW, James S, Ngadaya E et al. (2015) No evidence that polygynous marriage is a harmful cultural practice in northern Tanzania. Proc Natl Acad Sci U S A 112, 13827-13832.

36. Fantahun M, Berhane Y, Wall S et al. (2007) Women's involvement in household decision-making and strengthening social capital - crucial factors for child survival in Ethiopia. Acta Paediatr 96, 582-589.

37. Sodemann M, Rodrigues A, Nielsen J et al. (2005) Maternal vulnerability and socio-economic inequalities in child mortality. In Measuring Health Equity in Small Areas: Findings from Demographic Surveillance Systems, pp. 87-108 [INDEPTH Network editor]. London: Ashgate.

38. Obaa BB \& Mazur RE (2017) Social network characteristics and resource access among formerly displaced households in Lira, Uganda. Disasters 41, 468-486.

39. Waterston T, Alperstein G \& Brown SS (2004) Social capital: a key factor in child health inequalities. Arch Dis Child 89, 456-459.

40. Uganda Ministry of Health \& ICF International (2012) 2011 Uganda AIDS Indicator Survey: Key Findings. http://health. go.ug/docs/UAIS_2011_KEY_FINDINGS.pdf （accessed September 2017).

41. Leroy JL, Habicht JP, González de Cossío T et al. (2014) Maternal education mitigates the negative effects of higher income on the double burden of child stunting and maternal overweight in rural Mexico. $J$ Nutr 144, 765-470. 